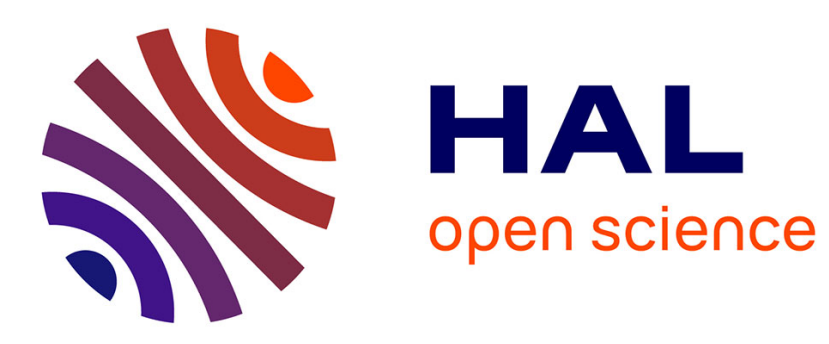

\title{
Agro-industrial waste to solid biofuel through hydrothermal carbonization
}

Daniele Basso, Francesco Patuzzi, Daniele Castello, Marco Baratieri, Elena

Cristina Rada, Elsa Weiss-Hortala, Luca Fiori

\section{- To cite this version:}

Daniele Basso, Francesco Patuzzi, Daniele Castello, Marco Baratieri, Elena Cristina Rada, et al.. Agroindustrial waste to solid biofuel through hydrothermal carbonization. Waste Management, 2016, 47 (Part A), pp.114-121. 10.1016/j.wasman.2015.05.013 . hal-01609111

\section{HAL Id: hal-01609111 \\ https://hal.science/hal-01609111}

Submitted on 2 May 2018

HAL is a multi-disciplinary open access archive for the deposit and dissemination of scientific research documents, whether they are published or not. The documents may come from teaching and research institutions in France or abroad, or from public or private research centers.
L'archive ouverte pluridisciplinaire HAL, est destinée au dépôt et à la diffusion de documents scientifiques de niveau recherche, publiés ou non, émanant des établissements d'enseignement et de recherche français ou étrangers, des laboratoires publics ou privés. 


\title{
Agro-industrial waste to solid biofuel through hydrothermal carbonization
}

\author{
Daniele Basso ${ }^{a}$, Francesco Patuzzi $^{\mathrm{b}}$, Daniele Castello ${ }^{\mathrm{a}}$, Marco Baratieri ${ }^{\mathrm{b}}$, Elena Cristina Rada ${ }^{\mathrm{a}}$, \\ Elsa Weiss-Hortala ${ }^{c}$, Luca Fiori ${ }^{\mathrm{a}, *}$ \\ a University of Trento, Department of Civil, Environmental and Mechanical Engineering, Italy \\ ${ }^{\mathrm{b}}$ Free University of Bolzano, Faculty of Science and Technology, Italy \\ ${ }^{\mathrm{c}}$ Université de Toulouse, Mines Albi, CNRS, Centre RAPSODEE, France
}

\begin{abstract}
A B S T R A C T
In this paper, the use of grape marc for energy purposes was investigated. Grape marc is a residual lignocellulosic by-product from the winery industry, which is present in every world region where vine-making is addressed. Among the others, hydrothermal carbonization was chosen as a promising alternative thermochemical process, suitable for the treatment of this high moisture substrate. Through a $50 \mathrm{~mL}$ experimental apparatus, hydrothermal carbonization tests were performed at several temperatures (namely: 180,220 and $250{ }^{\circ} \mathrm{C}$ ) and residence times $(1,3,8 \mathrm{~h}$ ). Analyses on both the solid and the gaseous phases obtained downstream of the process were performed. In particular, solid and gas yields versus the process operational conditions were studied and the obtained hydrochar was evaluated in terms of calorific value, elemental analysis, and thermal stability. Data testify that hydrochar form grape marc presents interesting values of $\mathrm{HHV}$ (in the range 19.8-24.1 MJ/kg) and physical-chemical characteristics which make hydrochar exploitable as a solid biofuel. In the meanwhile, the amount of gases produced is very small, if compared to other thermochemical processes. This represents an interesting result when considering environmental issues. Statistical analysis of data allows to affirm that, in the chosen range of operational conditions, the process is influenced more by temperature than residence time. These preliminary results support the option of upgrading grape marc toward its energetic valorisation through hydrothermal carbonization.
\end{abstract}

Keywords:
Biochar
Biofuel
Grape marc
Hydrochar
Hydrothermal carbonization
Thermochemical conversion

\section{Introduction}

Nowadays, the need for energy is a strong and relevant issue worldwide. The international community agrees that a strong effort should be made looking for alternative energy resources, capable to lower as much as possible the amount of fossil fuels from the energy portfolio and to develop a sustainable supply chain. At the same time, another important issue concerns waste management. As a matter of fact, proper waste management and treatment may allow both greenhouse gases (GHGs) mitigation and possibilities for bioenergy production (Pyo et al., 2014; Rada, 2014). These constraints are a strong driving force for the investigation on new and affordable technologies, able to combine proper

\footnotetext{
* Corresponding author at: University of Trento, Department of Civil, Environmental and Mechanical Engineering, via Mesiano 77, I-38123 Trento, Italy. Tel.: +390461282692, +390461282672.

E-mail address: luca.fiori@unitn.it (L. Fiori).
}

and sustainable waste management with the production of clean and renewable energy.

During the last decades, many processes have been proposed which could successfully address such issues. Such technologies can be classified as biological or thermochemical. In the general case, biological processes are quite sensitive with respect to the inlet feedstock as, potentially, microorganisms could be easily inhibited by toxic substances present in the substrate. Additionally, they need very long residence times (i.e. from one day to several weeks). Therefore, besides being slower, these processes entail bigger volumes, which cause higher design and manufacturing costs. On the contrary, the time scale of thermochemical processes generally ranges from a few minutes to some hours. Moreover, since such processes do not rely on microorganisms, they can overcome the limitations due to chemical lag and the possible inhibition by toxic agents, as described above. This is a noticeable advantage for the treatment of heterogeneous feedstock or substrates with a low degree of purity (e.g. organic wastes, sewage sludges, etc.). Several thermochemical processes have been 
proposed and discussed for the treatment of different kind of biowaste (Khoo, 2009; Iakovou et al., 2010; Devesa-Rey et al., 2011).

Referring to the type of feedstock, thermochemical processes can be divided into two main groups: dry and wet processes. The former, such as combustion or pyrolysis, are suitable when the feedstock has low water content. For example, several authors have discussed the application of these processes to woody agricultural biomass waste (Barbieri et al., 2013) or municipal solid wastes (Ragazzi and Rada, 2012; Abnisa and Wan Daud, 2014; Chen et al., 2014). When the feedstock presents high water content (i.e. moisture higher than 60\%), hydrothermal processes become more appropriate. These processes make use of hot pressurized water to convert wet substrates. Pressure is always held high enough to keep water in its liquid or, possibly, supercritical state. Among them, a classification on the basis of the process temperature and the type of obtained products can be done. When the temperature values range between $180^{\circ} \mathrm{C}$ and $250{ }^{\circ} \mathrm{C}$, the main product is a solid material (referred to as hydrochar) and the process is called hydrothermal carbonization (HTC) (Castello et al., 2014). If the temperatures are increased from $250^{\circ} \mathrm{C}$ to about $373^{\circ} \mathrm{C}$, hydrothermal liquefaction (HTL) is performed, with the main production of a liquid phase (Elliott et al., 2015). Finally, rising the temperature and the pressure above the critical values for water $\left(373.95^{\circ} \mathrm{C}\right.$ and $\left.22.06 \mathrm{MPa}\right)$, the process is called hydrothermal gasification (HTG) or supercritical water gasification (SCWG), which allows for a combustible gas as main product (Castello et al., 2014). The application of these hydrothermal processes to several typologies of biomass has been discussed by many authors (Fiori et al., 2012a; Lu et al., 2012; Pala et al., 2014; Xiao et al., 2012; Subagyono et al., 2014; Yedro et al., 2014).

The type of feedstock is another important aspect to be considered in order to guarantee an appropriate degree of both sustainability and profitability. In particular, the ready availability of the biomass on the territory around the treatment plant, as well as its cost, is crucial. As a matter of fact, when a substrate is produced as a by-product of agricultural and industrial activities established nearby the conversion plant, its supply and transportation costs are lowered, which is beneficial to the overall economic balance of the energy production process. Additionally, such choice improves the sustainability of the process by reducing the polluting emissions due to biomass transportation over long distances. Moreover, if the company that produced that by-product is also in charge of its disposal, the possibility to collect this by-product as a feedstock for energy purposes can represent an interesting, viable and advantageous alternative.

In the region in which the present research group is operating (i.e. the North-East of Italy), grape marc is widely available, as it is an important by-product of the wine making industries. Grape marc already has a utilization for the production of spirits through distillation. However, downstream of such process, most residual grape marc is still found as a wet ligno-cellulosic residue, which must be properly disposed of. HTC could be an effective technology to achieve both the disposal and valorisation of such feedstock.

Considering that HTC is performed at milder operational conditions than the other hydrothermal processes, this process has been investigated in the present paper as a suitable way to energetically valorise the grape marc by-product which is affordable also at the SME (Small and Medium Enterprise) level.

In this paper, the results of HTC of grape marc performed in a lab scale batch reactor are presented. Several reaction conditions were explored, including different reaction temperatures and residence times. Both solid and gaseous products were sampled and analyzed. The energy content, the elemental analysis and the thermal stability of the solid was determined, showing the great potentiality of hydrochar as a fuel. Analyses on the gaseous phase were performed both to try to understand the chemical processes occurring during HTC and to get information on the gaseous emissions on the environment.

\section{Materials and methods}

\subsection{The feedstock}

Grape marc collected after wine production consists of seeds, skins and, possibly, stalks. Actually, stalks are collected together with seeds and skins or, vice versa, separately according to the different wine-making procedures. Usually, when grape marc originates from the wine-making process, it is referred to as "fresh grape marc", while after it has been used for spirits production, it is referred to as "exhausted grape marc". In the case of fresh grape marc, the moisture content ranges between $60 \%$ and $70 \%$ (Fiori and Florio, 2010). Thus, after a drying pre-treatment, which could be addressed also through innovative technologies such as bio-drying (Rada et al., 2009), grape marc can be exploited for energy purposes through conventional thermochemical processes such as combustion or pyrolysis (Fiori et al., 2012b). Alternatively, it can undergo hydrothermal treatments, like the HTC here investigated.

For the present research, fresh grape marc was collected at a wine-production site located in Trentino (North-East of Italy). The raw feedstock was dried in a ventilated oven at $65^{\circ} \mathrm{C}$ for about $48 \mathrm{~h}$. Subsequently, grape marc was let cooling down to room temperature and finally stored into plastic bags, until use. The final average moisture was measured to be about $5 \%$. This kind of pre-treatment was performed in order to collect data regardless of the degree of moisture of the incoming feedstock, which could be variable. Furthermore, this drying pre-treatment was necessary to prevent the degradation of the feedstock during the period between its collection and its actual utilization for the experiments (up to some weeks). The presence of water would have caused undesired degradation reactions, as well as mould formation, which would have altered the quality and composition of the substrate in a significant way. Nevertheless, when applying HTC to grape marc in a real industrial process, wet grape marc would most likely be used as received and possibly applying additional quantities of water, in order to reach the optimal biomass to water $(\mathrm{B} / \mathrm{W})$ ratio.

\subsection{The HTC experimental apparatus}

As explained above, the hydrothermal carbonization is usually performed in a temperature range of $180-250^{\circ} \mathrm{C}$. Since water has to be maintained in its liquid state, pressures reach values of 40-50 bar. Therefore, a $50 \mathrm{~mL}$ stainless steel (AISI 316) batch reactor was designed and built, with a design temperature and pressure of $300^{\circ} \mathrm{C}$ and $140 \mathrm{bar}$, respectively. For further technical information, the reader can refer to Basso et al. (2015). The experimental apparatus was equipped with a thermocouple embedded inside the reactor. For the measurement of the pressure, both a pressure gauge and a pressure recorder were used.

\subsection{Experimental procedure}

The reactor was filled with $5.4 \pm 0.1 \mathrm{~g}$ of feedstock and $27.0 \pm 0.1 \mathrm{~g}$ of distilled water, obtaining a biomass to water ratio of about 0.19 (dry basis). The reactor was sealed with a copper gasket and then it was closed. Before each test, nitrogen was flushed within the reactor to purge it from the presence of air. The reactor was warmed up through a band heater. At the end of each test, the reactor was quenched with the help of a stainless steel block kept at $-26^{\circ} \mathrm{C}$ which was put underneath the reactor itself, while fresh 
compressed air was blown onto it. To both warm up and quench the reactor, about $15-20 \mathrm{~min}$ were required. The residence times here considered refer to the period between the reaching of the set temperature and the starting of the quenching. Three temperatures and three residence times were chosen for the experiments: $180^{\circ} \mathrm{C}, 220^{\circ} \mathrm{C}, 250^{\circ} \mathrm{C}$ at $1 \mathrm{~h}, 3 \mathrm{~h}$ and $8 \mathrm{~h}$. Test runs corresponding to all the 9 combinations of such parameters were executed.

The experimental apparatus did not allow for the simultaneous measure of both the volume and the composition of the gas produced during the process. Thus, tests were repeated twice at the same conditions in order to measure separately the volume of the produced gas and its composition. All the gas composition measurements were repeated three times. The volume of the produced gas was measured directly in one series of tests, while in the other series (where the gas composition was measured), it was calculated considering the measured reactor residual pressure after quenching. In all the repetitions, temperature and pressure profiles showed a deviation never higher than $1.0 \%$ and $1.4 \%$, respectively.

\subsection{Measurements and analyses of the solid phase}

At the end of each run, the reactor was opened. Its content was filtered and both liquid and solid products were collected. The wet filter and the reactor, both holding a certain amount of solids, were dried in an oven at $105^{\circ} \mathrm{C}$ for at least $8 \mathrm{~h}$. After drying, the filter and the reactor were weighed again. The hydrochar yield was then determined in terms of amount of solid recovered with respect to the amount of substrate initially loaded into the reactor, i.e. $\mathrm{kg}_{\text {hydrochar }}$ per $\mathrm{kg}_{\text {dry feed. }}$.

The energy content of the hydrochar was assessed measuring the higher heating value (HHV) of powdered samples in a calorimetric bomb (IKA 200C). Isoperibolic method was applied in accordance with UNI EN 14918:2010.

The elemental analysis was carried out in a Thermo NA 2100 to obtain $\mathrm{C}, \mathrm{H}, \mathrm{N}$, and $\mathrm{S}$ mass fractions. The ash content was then determined by incineration at $550^{\circ} \mathrm{C}$ according to EN 14775 procedure. The $\mathrm{O}$ content was deduced by difference.

The thermo-gravimetric analysis (TGA) of solid samples was carried out in a TG-DTA LabSys Evo (Setaram). About $20 \mathrm{mg}$ of each sample were heated from 30 to $800^{\circ} \mathrm{C}$ in a nitrogen atmosphere at $5{ }^{\circ} \mathrm{Cmin}^{-1}$.

\subsection{Measurements and analyses of the gaseous phase}

To measure the amount of gas formed during the HTC process, a simple experimental apparatus consisting of a plastic graduated cylinder with the lower part submerged into water was used. Before each measurement, vacuum was created inside the cylinder through a pump, to raise the water meniscus up to the zero of the graduated scale. The zero was positioned on the upper part of the cylinder, with the graduated scale (in $\mathrm{cm}$ ) facing downwards. Thus, a needle valve was opened and the gas flowed inside the cylinder, causing the water level to decrease. The difference between the initial and the final position of the meniscus allowed the calculation of the volume of formed gas.

For the analyses of the gaseous phase composition, a mobile micro-GC (Agilent 3000), equipped with a MOLSIEVE and a PLOT $\mathrm{U}$ column was used. Detectable components were $\mathrm{H}_{2}, \mathrm{~N}_{2}, \mathrm{O}_{2}, \mathrm{CO}$, $\mathrm{CH}_{4}, \mathrm{CO}_{2}, \mathrm{C}_{2} \mathrm{H}_{6}$ and $\mathrm{C}_{2} \mathrm{H}_{4}$.

\subsection{Statistical analysis of data}

ANOVA was performed to get insights on the influence of both temperature and residence time on three different variables: hydrochar yield, hydrochar HHV and gas composition. As far as hydrochar yield is concerned, the data used for the statistical analysis are relevant to experimental tests repeated twice. Thus, for this variable two-way ANOVA with two replications was performed (with significance level $\alpha=0.05$ ).

On the contrary, the hydrochar HHV was measured only once. Thus, two-way ANOVA without replications (with $\alpha=0.05$ ) was performed for HHV.

The gas composition was measured three times by the micro-GC, although these measurements are relevant to the same HTC test (see Section 2.3). For the gas composition two-way ANOVA without replications (with $\alpha=0.05$ ) was performed, taking the values of the gas composition as the average (arithmetic mean) of the three measurements.

To perform ANOVA the following Ms Excel Data Analysis tools were used: "Anova: Two-Factor With Replications" for hydrochar yield, and "Anova: Two-Factor Without Replication" for both HHV and gas composition.

\section{Results and discussion}

\subsection{Experimental runs}

In Fig. 1 typical temperature and the pressure profiles are represented, with reference to an experimental run performed for $8 \mathrm{~h}$ at $250^{\circ} \mathrm{C}$.

In about $20 \mathrm{~min}$ the reactor reaches the set point temperature (in the case shown, $250^{\circ} \mathrm{C}$ ), that is then kept constant for the selected residence time (in this case, $8 \mathrm{~h}$ ). At the end of the process, the reactor is quenched and this operation takes again about $20 \mathrm{~min}$. An initial increase of the temperature above $250^{\circ} \mathrm{C}$ can be observed: this is due to the time delay in heat transfer from the heat source (band heater) to the thermocouple providing the temperature value to the temperature controller.

It can be observed that the temperature along the whole run is kept constant, while the pressure slightly increases with time. This increase is due to the formation of gas during the HTC process. An interesting comparison can be made with the NIST steam tables data (NIST, 2015), represented by the light gray solid line in Fig. 1. The gas formed from the feedstock is responsible for the difference between the vapor pressure $\left(39.762\right.$ bar at $250^{\circ} \mathrm{C}$, NIST, 2015) and the actual pressure measured during HTC. It can be appreciated that gas is formed in the early stages of the process: immediately after the heating up phase, differences between the actual pressure and the vapor pressure become evident. The gas production does not follow a linear trend, but it is more remarkable at the beginning of the process, while it decreases increasing the residence time. Finally, when the system is cooled down, the residual pressure within the reactor testifies once more that a non-negligible amount of gas formed during HTC.

\subsection{Hydrochar yield}

Fig. 2 shows the hydrochar yield for all the performed tests and its dependence on process temperature and residence time. Hydrochar yield ranges from 0.76 (temperature: $180^{\circ} \mathrm{C}$; residence time: $1 \mathrm{~h}$ ) to 0.56 (temperature: $250^{\circ} \mathrm{C}$; residence time: $8 \mathrm{~h}$ ). Similar results have been obtained by Pala et al. (2014), performing HTC on grape pomace. The increase in process temperature and residence time causes the hydrochar yield to decrease (and the production of gas to increase, Fig. 4). In the range of operating conditions investigated, the effect of the process temperature is much greater than that of the residence time. As a matter of fact, the two-way ANOVA results confirmed that the temperature affects the hydrochar yield $(F>\mathrm{Fc}$ and $p=0.002$ ), while the residence time cannot be considered statistically relevant $(F<\mathrm{Fc}$ and $p=0.173$ ). Moreover, it is not possible to affirm that the effect of interactions 


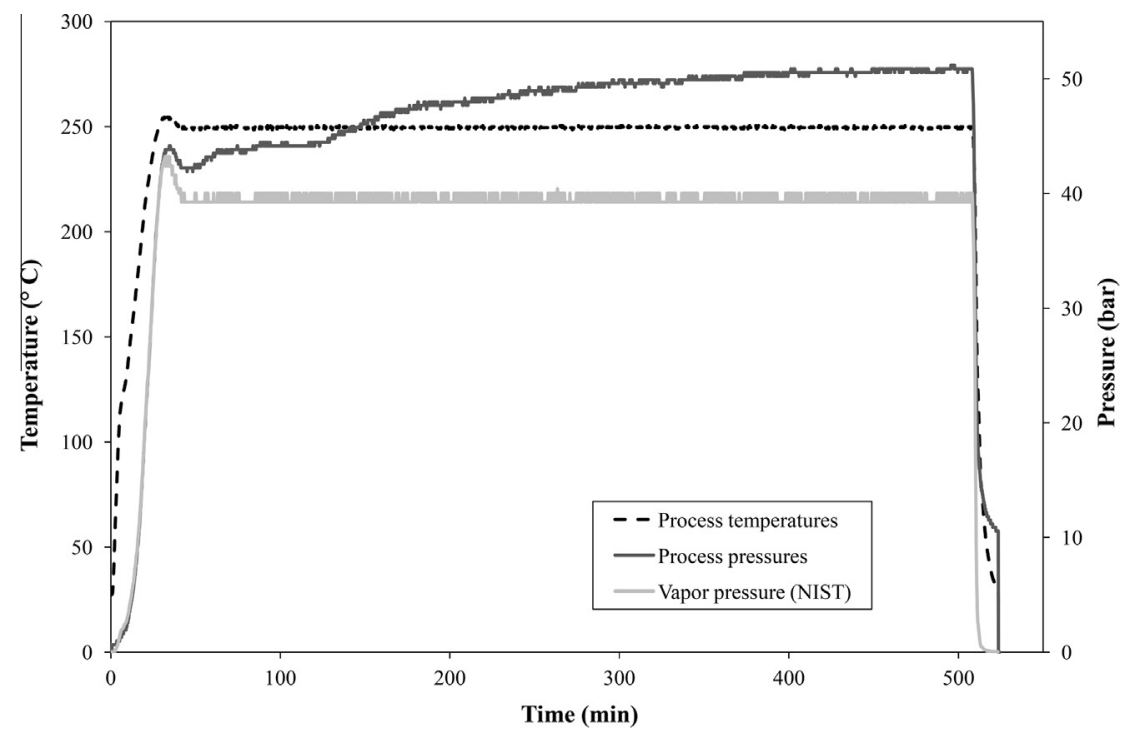

Fig. 1. Trends of temperature and pressure during an experimental run (set point temperature: $250{ }^{\circ} \mathrm{C}$; residence time: $8 \mathrm{~h}$ ); vapor pressure data are also reported (NIST, 2015 ).

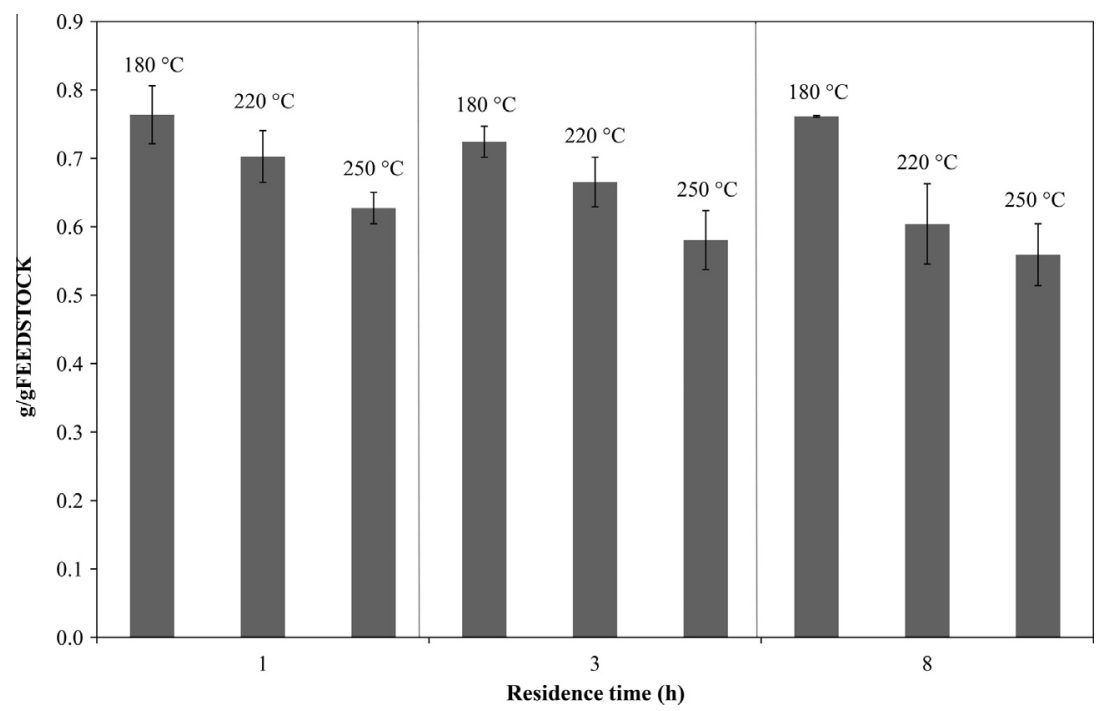

Fig. 2. Hydrochar yield (average of two replications \pm standard deviation) at different temperatures and residence times.

between temperature and residence time is statistically significant $(F<$ Fc and $p=0.514)$.

The minor influence of the residence time on the hydrochar yield is particular evident at $180^{\circ} \mathrm{C}$ : the hydrochar yields are nearly coincident for all residence times analyzed. At 220 and $250^{\circ} \mathrm{C}$, the system seems more reactive and the effect of residence time can be noticed (in terms of the average values).

This could be explained by referring to the main reactions typically taking place during HTC. Some authors (Funke and Ziegler, 2010; Libra et al., 2011) suggested that such reactions include: hydrolysis of the feedstock, dehydration, decarboxylation, decarbonylation, condensation, and polymerization. In particular, Funke and Ziegler (2010) reported that, when carbonizing lignocellulosic materials, hemicellulose readily hydrolyzes from $180^{\circ} \mathrm{C}$, while both cellulose and lignin are hydrothermally degraded at temperatures higher than $200{ }^{\circ} \mathrm{C}$. Therefore, the almost constant yields at $180^{\circ} \mathrm{C}$ shown in Fig. 2 could be due to the fact that only hemicellulose is degraded and that such conversion is achieved in the first stage of reaction (i.e. up to $1 \mathrm{~h}$ ). Thus, at $180^{\circ} \mathrm{C}$ the residence time does not contribute to the degradation of the feedstock to both liquid and gaseous products.

\subsection{Gas phase: composition and production}

Fig. 3 reports the data obtained from the measurements with the portable micro-GC. $\mathrm{CO}_{2}$ is the gas formed the most during HTC, with molar fractions ranging from $94 \%$ to $99 \%$ (Fig. 3a). At $180{ }^{\circ} \mathrm{C}$ almost all the gas formed is composed of $\mathrm{CO}_{2}$ (98-99\%). Increasing the temperature, relatively less $\mathrm{CO}_{2}$ is formed while the $\mathrm{CO}$ production increases. Referring to Fig. 3a and b, the influence of the residence time at $220^{\circ} \mathrm{C}$ is negligible, while it is more pronounced at $250^{\circ} \mathrm{C}$. Moreover, an interesting effect can be appreciated from both Fig. $3 \mathrm{a}$ and b. At $180^{\circ} \mathrm{C}$, increasing the reaction time causes the molar fraction of $\mathrm{CO}_{2}$ to decrease slightly and the molar fraction of $\mathrm{CO}$ to increase slightly. At $220^{\circ} \mathrm{C}$, the reaction time has no effect of the relative amount of $\mathrm{CO}_{2}$ and $\mathrm{CO}$. At $250^{\circ} \mathrm{C}$, increasing the reaction time causes the molar fraction of $\mathrm{CO}_{2}$ to increase and the molar fraction of $\mathrm{CO}$ to decrease, thus the trend 

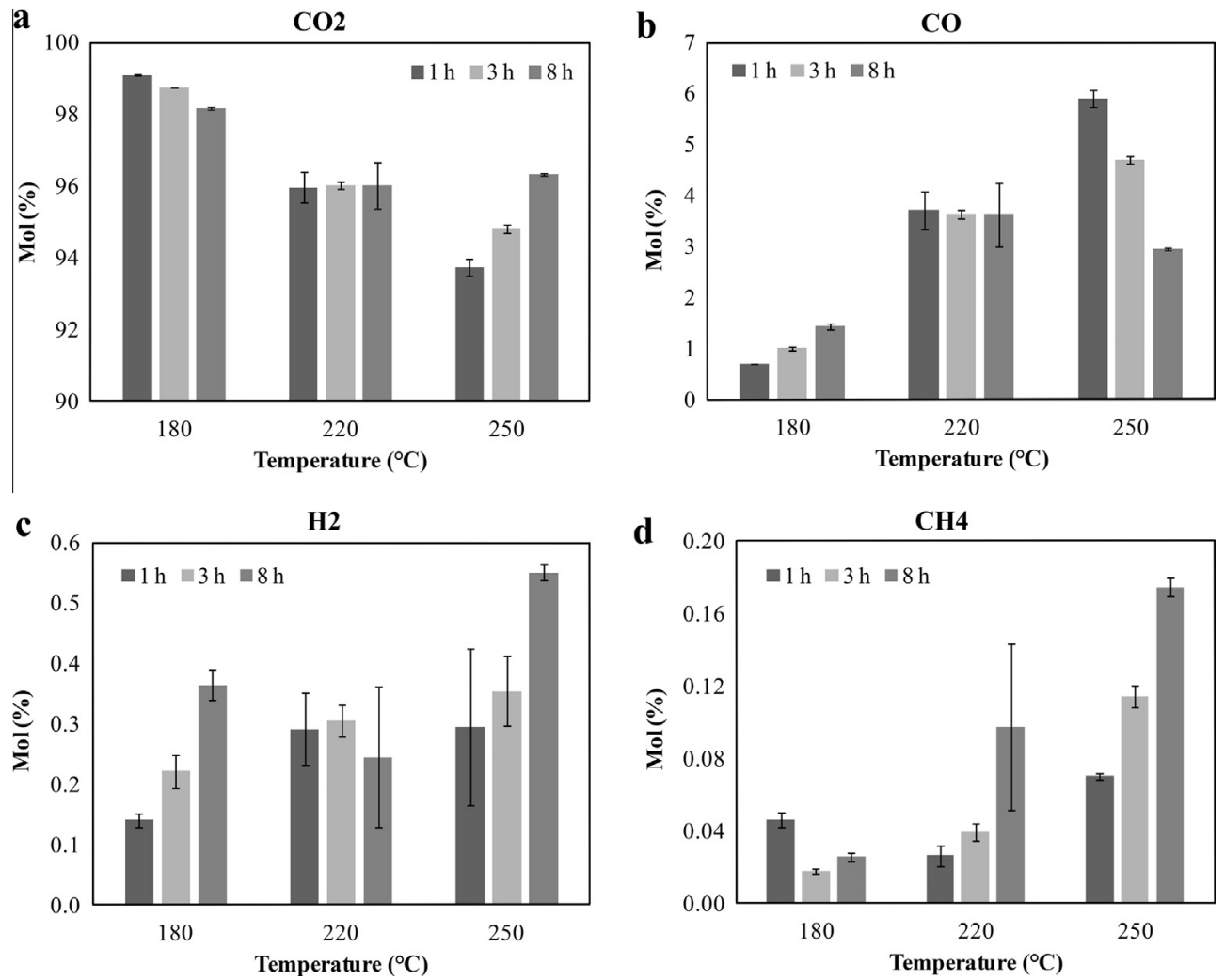

Fig. 3. Gas phase molar composition (average of three replications \pm standard deviation) at different temperatures and residence times: (a) $\mathrm{CO}_{2}$; (b) $\mathrm{CO}_{\text {; }}(\mathrm{c}) \mathrm{H}_{2}$; (d) $\mathrm{CH}_{4}$.

is opposite to that detected at $180^{\circ} \mathrm{C}$. A possible explanation to this phenomenon could be that, at low residence times, de-carboxylation reactions are favored at low temperatures, while high temperatures tend to favor de-carbonylation. At $250^{\circ} \mathrm{C}$, the decrease of $\mathrm{CO}$ at increasing residence time, and the corresponding increase of $\mathrm{H}_{2}$ and $\mathrm{CO}_{2}$, are most likely an effect of the water-gas shift reaction (Castello et al., 2015) which can effectively take place at the considered reaction conditions. At $180^{\circ} \mathrm{C}$, the decrease of $\mathrm{CO}_{2}$ at increasing residence time could be related to some reductive processes taking place in the aqueous phase. The tests at the intermediate temperature $\left(220^{\circ} \mathrm{C}\right)$ do not show a relevant dependence on the residence time since, probably, such two tendencies balance each other. Further work should be performed to better explain this issue.

Fig. $3 c$ and d shows that, in all process conditions, both $\mathrm{H}_{2}$ and $\mathrm{CH}_{4}$ are produced in trace amounts.

The two-way ANOVA performed on the gas composition data allowed to state that both temperature and residence time affect the gas production for all the gases $(F>\mathrm{FC}$ and $p<\alpha)$.

Fig. 4 reports the total gas production at the different conditions. The gas production trends are clear: the increase of both temperature and residence time results in an enhancement of the gaseous phase produced by HTC. This result is in agreement with that obtained for the hydrochar yield (Fig. 2): increasing the severity of the process causes higher degradation of the solid feedstock in favor of the gaseous products. Furthermore, Fig. 4 shows how the effect of temperature is stronger if compared to that of residence time. As a matter of fact, the increase of the produced gas at increasing residence time (at fixed temperature) is lower than that at increasing temperatures (at fixed residence time). This is further evidence that the main reactions involved in HTC mostly take place in the first stage of the process. Hence, further research should focus on the reaction steps that characterize the first hour of operations. Finally, the results shown in Fig. 4 confirm that the amount of gas produced during HTC is smaller if compared to that of other thermochemical processes. Hence, when considering HTC industrial applications, this fact will ease the management of environmental issues.

\subsection{Hydrochar characterization}

In Fig. 5 the HHVs of the hydrochar obtained at different HTC conditions were reported. On the $x$-axis, the label "RF" stands for "raw feedstock", i.e. dried grape marc.

The increase in HHV due to HTC is significant, ranging from $24 \%$ (residence time: $1 \mathrm{~h}$; temperature: $180^{\circ} \mathrm{C}$ ) to $54 \%$ (residence time: $8 \mathrm{~h}$; temperature: $250^{\circ} \mathrm{C}$ ). These values of energy densification seem to be consistent with those obtained by Pala et al. (2014). Performing HTC of several municipal solid wastes, Lu et al. (2011) obtained an increase in HHV ranging from $1 \%$ to $41 \%$ (residence time: $30 \mathrm{~min}$; temperature: $220^{\circ} \mathrm{C}$ ), values comparable to those here obtained.

The two-way ANOVA allows to state that both temperature and residence time affect the HHV of the hydrochar $(F>$ Fc and $p<\alpha)$. Also the HHV data of Fig. 5 corroborate the conclusions above reported when discussing on hydrochar and gas yields (Sections 3.2 and 3.3): the influence of process temperature is greater than that of residence time. This is in clear agreement with previous literature results (Funke and Ziegler, 2011; Gaji et al., 2012; Liu and Balasubramanian, 2012). As a matter of fact, an increase in temperature favors dehydration and the decarboxylation reactions, which corresponds to a decrease in the content of both oxygen and hydrogen in the feedstock. Similar results were found also by other authors (Heilmann et al., 2011; Dinjus et al., 2011; Mumme et al., 2011).

The elemental analysis (Table 1) clearly shows that the carbon content of the hydrochars increases with temperature and residence time and, correspondingly, the oxygen content decreases. 


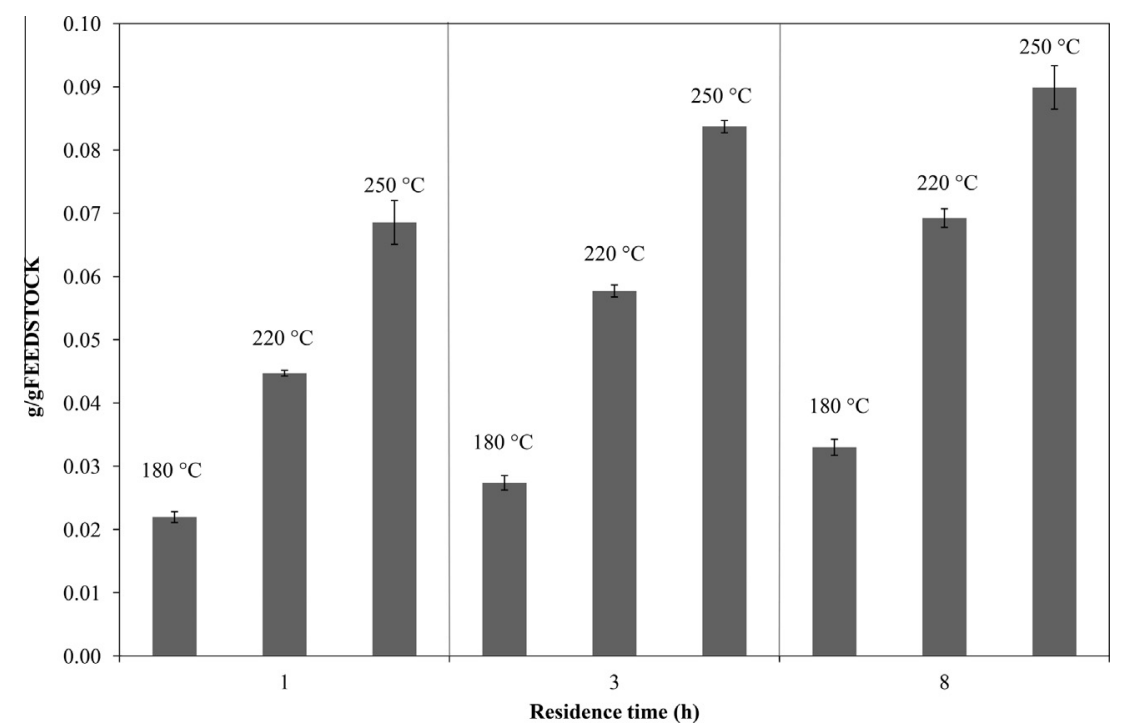

Fig. 4. Gas yield (average of two replications \pm standard deviation) at different temperatures and residence times.

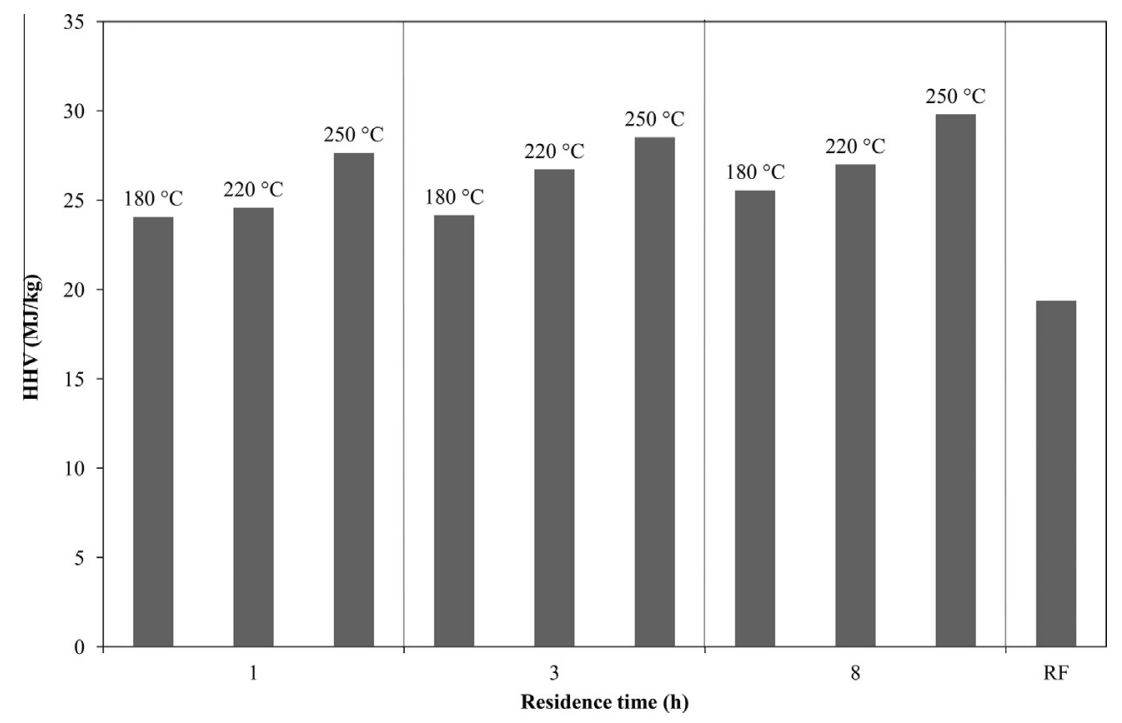

Fig. 5. HHVs at different temperatures and residence times.

Table 1

Elemental analysis: values in wt.\%.

\begin{tabular}{|c|c|c|c|c|c|c|c|c|}
\hline Residence time (h) & Temperature $\left({ }^{\circ} \mathrm{C}\right)$ & C & $\mathrm{H}$ & 0 & $\mathrm{~N}$ & Ash & $\mathrm{H} / \mathrm{C}$ & $\mathrm{O} / \mathrm{C}$ \\
\hline Grape marc (dried) & & 49.71 & 6.15 & 35.57 & 2.43 & 6.00 & 1.49 & 0.54 \\
\hline 1 & 180 & 56.21 & 5.88 & 31.99 & 2.53 & 3.38 & 1.26 & 0.43 \\
\hline 3 & 180 & 56.98 & 5.64 & 30.18 & 2.58 & 4.62 & 1.19 & 0.40 \\
\hline 8 & 180 & 57.23 & 5.71 & 29.67 & 2.78 & 4.62 & 1.20 & 0.39 \\
\hline 1 & 220 & 59.85 & 5.74 & 28.00 & 2.59 & 3.83 & 1.15 & 0.35 \\
\hline 3 & 220 & 62.47 & 5.43 & 25.85 & 2.72 & 3.53 & 1.04 & 0.31 \\
\hline 8 & 220 & 64.10 & 5.66 & 24.02 & 2.24 & 3.98 & 1.06 & 0.28 \\
\hline 1 & 250 & 64.94 & 5.80 & 22.40 & 2.77 & 4.09 & 1.07 & 0.26 \\
\hline 3 & 250 & 65.58 & 6.00 & 20.35 & 2.81 & 5.26 & 1.10 & 0.23 \\
\hline 8 & 250 & 68.07 & 5.81 & 19.36 & 2.56 & 4.20 & 1.02 & 0.21 \\
\hline
\end{tabular}

Vice versa, the relative abundance of hydrogen, nitrogen, and ash seems not affected by the severity of the process. The content of sulfur, extremely small and often measured equal to zero, was not reported in Table 1.

The compositional data reported in Table 1 support the energy densification results previously discussed: the higher is the carbon content of the substrate, the higher its HHV. Importantly, the atomic ratio $\mathrm{O} / \mathrm{C}$ decreases drastically with process time and temperature: from 0.54 (raw biomass) to 0.21 (residence time: $8 \mathrm{~h}$; temperature: $250^{\circ} \mathrm{C}$ ). Referring to the van Krevelen's diagram (Basso et al., 2015), the HTC process provides hydrochars in the region of biomass/peat when the process temperature is $180^{\circ} \mathrm{C}$, 
and in the region of peat for more severe process conditions. Actually, the hydrochar obtained after $8 \mathrm{~h}$ at $250^{\circ} \mathrm{C}$ is in the region of lignite.

Results from TGA testify that the mass loss of the hydrochar samples during analysis greatly reflects the HTC operational conditions: the mass loss is in the range of 65.7-67.9 wt.\% for the hydrochars obtained at $180^{\circ} \mathrm{C}$, while it is comprised between 51.8 and $57.2 \mathrm{wt} . \%$ for the hydrochars obtained at $250{ }^{\circ} \mathrm{C}$ (complete set of results not shown).

The derivative mass loss (DTG) is reported in Fig. 6 for five samples including the raw material and the hydrochars obtained after 1 or $8 \mathrm{~h} \mathrm{HTC}$ treatment at 180 or $250{ }^{\circ} \mathrm{C}$.

For the raw sample, a large peak of DTG is observed at low temperature with three relative minima at 80,102 and $134^{\circ} \mathrm{C}$. These peaks are due to dehydration and release of volatile compounds. After HTC treatment, the peak appears to be only centred at $80^{\circ} \mathrm{C}$, likely due to residual water content. Therefore, the HTC treatment impacts the presence of volatile compounds in the remaining solid.

Raw sample shows three other main peaks centred at 262, 310 , and $408^{\circ} \mathrm{C}$. These peaks correspond to the thermo-degradation of organic compounds present in the grape marc.

Considering hydrochars obtained at low temperature $\left(180^{\circ} \mathrm{C}\right)$, the main mass loss is represented by a peak centred at a temperature of about $337^{\circ} \mathrm{C}$. Interestingly, such peak is more intense than the peaks of grape marc, meaning that new compounds are produced during HTC. Moreover, this peak is slightly shifted to a higher temperature if compared to the peak detected for the raw material $\left(310^{\circ} \mathrm{C}\right)$, meaning that the new compounds are slightly more stable. At the highest treatment temperature (temperature: $250{ }^{\circ} \mathrm{C}$; residence time: $1 \mathrm{~h}$ ), the peak is shifted to $371^{\circ} \mathrm{C}$, testifying that the new formed compounds are even more stable.

HTC has a clear impact on the compounds which are degraded at $262^{\circ} \mathrm{C}$, as the peak is much less intense after HTC. Thus, a large part of these compounds were removed during HTC.

The peak centred at $410^{\circ} \mathrm{C}$ is also impacted by HTC, as its intensity increases with the increase of temperature and residence time. The highest impact is found for the most severe conditions (temperature: $250^{\circ} \mathrm{C}$; residence time: $8 \mathrm{~h}$ ).

To summarize the information contained in Fig. 6, the increase of temperature and residence time causes a decrease in the amount of volatile compounds and thermo-sensitive molecules, and results in an increase in thermal stable compounds in the hydrochar. This is in complete agreement with the compositional data of Table 1: the increase in carbon content indicates an increase in "fixed carbon", which is testified by the increased thermal stability proved by TGA. In addition, as previously discussed, the increase of carbon

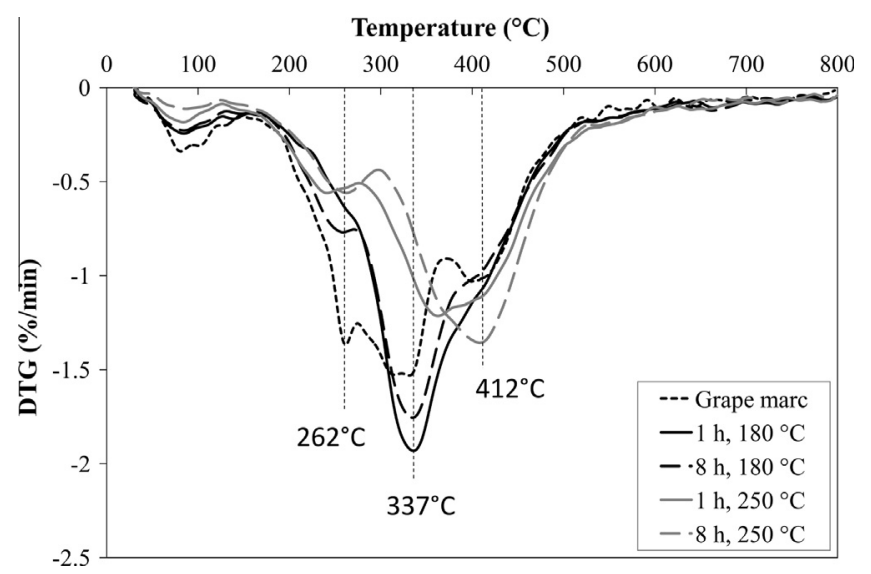

Fig. 6. Hydrochar thermal stability: TGA results. content sustains the higher HHV of the hydrochar produced at the most severe conditions, as shown in Fig. 5.

\section{Conclusions}

In this paper, hydrothermal carbonization was studied as a viable process to energetically valorise grape marc. In particular, the research was performed with an experimental apparatus, through which several tests were carried out at different temperatures and residence times.

The results obtained for both solid and gaseous products showed that temperature is the main parameter affecting the process. An increase in temperature reduces hydrochar mass yields in favor of the gaseous phase. Despite less solid formed, the hydrochar produced at higher temperature has a higher carbon content and thus a higher HHV. At $250^{\circ} \mathrm{C}$, the HHV increase due to HTC is significant, and varied from $43 \%$ to $54 \%$, depending on residence time. Conversely, the increase in HHV was only equal to $24 \%$ at the less severe process conditions $\left(1 \mathrm{~h}, 180^{\circ} \mathrm{C}\right)$. In addition, increasing the severity of the process greatly increases the thermal stability of the hydrochar produced.

The gaseous phase is mainly composed by $\mathrm{CO}_{2}$, with some $\mathrm{CO}$ being generated at higher temperatures. Other molecules, such as $\mathrm{H}_{2}$ and $\mathrm{CH}_{4}$, are only produced in traces. Their amounts tend to increase when more severe process conditions are adopted.

HTC seems to have great potentialities for meeting the challenges of both energetically valorising winery industry residues and improving their management. Future research will include in-deep analyses of the liquid phase, in order to better understand the chemical reactions occurring during HTC. Moreover, to address real industrial applications of the HTC process, an economic evaluation is mandatory.

\section{References}

Abnisa, F., Wan Daud, W.M.A., 2014. A review on co-pyrolysis of biomass: an optional technique to obtain a high-grade pyrolysis oil. Energy Convers. Manage. 87, 71-85. http://dx.doi.org/10.1016/j.enconman.2014.07.007.

Barbieri, L. Andreola, F. Lancellotti, I., Taurino, R, 2013. Management of agricultural biomass wastes: preliminary study on characterization and valorisation in clay matrix bricks. Waste Manage. 33 (11), 2307-2315. http://dx.doi.org/10.1016/ j.wasman.2013.03.014.

Basso, D., Weiss-Hortala, E., Patuzzi, F., Castello, D., Baratieri, M., Fiori, L., 2015 Hydrothermal carbonization of off-specification compost: a byproduct of the organic municipal solid waste treatment. Bioresour. Technol. 182, 217-224. http://dx.doi.org/10.1016/j.biortech.2015.01.118.

Castello, D., Kruse, A., Fiori, L., 2014. Supercritical water gasification of hydrochar Chem. Eng. Res. Des. 92 (10), 1864-1875. http://dx.doi.org/10.1016/ j.cherd.2014.05.024.

Castello, D., Kruse, A., Fiori, L., 2015. Low temperature supercritical water gasification of biomass constituents: glucose/phenol mixtures. Biomass Bioenergy 73, 84-94. http://dx.doi.org/10.1016/j.biombioe.2014.12.010.

Chen, D., Yin, L., Wang, H., He, P., 2014. Pyrolysis technologies for municipal solid waste: a review. Waste Manage. 34 (12), 2466-2486. http://dx.doi.org/10.1016/ j.wasman.2014.08.004

Devesa-Rey, R., Vecino, X., Varela-Alende, J.L., Barral, M.T., Cruz, J.M., Moldes, A.B., 2011. Valorization of winery waste vs. the costs of not recycling. Waste Manage. 31 (11), 2327-2335. http://dx.doi.org/10.1016/j.wasman.2011.06.001.

Dinjus, E., Kruse, A., Troger, N., 2011. Hydrothermal Carbonization - 1. Influence of lignin in lignocelluloses. Chem. Eng. Technol. 34 (12), 2037-2043. http:// dx.doi.org/10.1002/ceat.201100487.

Elliott, D.C., Biller, P., Ross, A.B., Schmidt, A.J., Jones, S.B., 2015. Hydrothermal liquefaction of biomass: developments from batch to continuous process. Bioresour. Technol. 178, 147-156. http://dx.doi.org/10.1016/ j.biortech.2014.09.132.

Fiori, L., Florio, L., 2010. Gasification and combustion of grape marc: comparison among different scenarios. Waste Biomass Valoriz. 1 (2), 191-200. http:// dx doi.org/10.1007/s12649-010-9025-7.

Fiori, L., Valbusa, M., Castello, D., 2012a. Supercritical water gasification of biomass for $\mathrm{H}_{2}$ production: process design. Bioresour. Technol. 121, 139-147. http:// dx.doi.org/10.1016/j.biortech.2012.06.116.

Fiori, L., Valbusa, M., Lorenzi, D., Fambri, L., 2012b. Modeling of the devolatilization kinetics during pyrolysis of grape residues. Bioresour. Technol. 103, 389-397. http://dx.doi.org/10.1016/j.biortech.2011.09.113. 
Funke, A., Ziegler, F., 2010. Hydrothermal carbonization of biomass: a summary and discussion of chemical mechanisms for process engineering. Biofuel Bioprod. Biorefining 4 (2), 160-177. http://dx.doi.org/10.1002/bbb.198.

Funke, A., Ziegler, F., 2011. Heat of reaction measurements for hydrothermal carbonization of biomass. Bioresour. Technol. 102 (16), 7595-7598. http:// dx.doi.org/10.1016/j.biortech.2011.05.016.

Gaji, A., Ramke, H.G., Hendricks, A., Koch, H.J., 2012. Microcosm study on the decomposability of hydrochars in a Cambisol. Biomass Bioenergy 47, 250-259. http://dx.doi.org/10.1016/j.biombioe.2012.09.036.

Heilmann, S.M., Jader, L.R., Sadowsky, M.J., Schendel, F.J., Von Keitz, M.G., Valentas, K.J., 2011. Hydrothermal carbonization of distiller's grains. Biomass Bioenergy 35 (7), 2526-2533. http://dx.doi.org/10.1016/j.biombioe.2011.02.022.

Iakovou, E., Karagiannidis, A., Vlachos, D., Toka, A., Malamakis, A., 2010. Waste biomass-to-energy supply chain management: a critical synthesis. Waste Manage. 30 (10), 1860-1870. http://dx.doi.org/10.1016/j.wasman.2010.02.030.

Khoo, H.H., 2009. Life cycle impact assessment of various waste conversion technologies. Waste Manage. 29 (6), 1892-1900. http://dx.doi.org/10.1016/ j.wasman.2008.12.020.

Libra, J.A., Ro, K.S., Kammann, C., Funke, A., Berge, N.D., Neubauer, Y., Titirici, M.-M., Fühner, C., Bens, O., Kern, J., Emmerich, K.-H., 2011. Hydrothermal carbonization of biomass residuals : a comparative review of the chemistry, processes and applications of wet and dry pyrolysis. Biofuels 2 (1), 89-124, doi:10.4155bfs. 10.81

Liu, Z., Balasubramanian, R., 2012. Hydrothermal carbonization of waste biomass for energy generation. Proc. Environ. Sci. 16, 159-166. http://dx.doi.org/ 10.1016/j.proenv.2012.10.022.

Lu, L., Namioka, T., Yoshikawa, K., 2011. Effects of hydrothermal treatment on characteristics and combustion behaviors of municipal solid wastes. Appl. Energy 88 (11), 3659-3664. http://dx.doi.org/10.1016/j.apenergy.2011.04.022.

Lu, X. Jordan, B., Berge, N.D., 2012. Thermal conversion of municipal solid waste via hydrothermal carbonization: comparison of carbonization products to products from current waste management techniques. Waste Manage. 32 (7), 13531365. http://dx.doi.org/10.1016/j.wasman.2012.02.012.
Mumme, J., Eckervogt, L., Pielert, J., Diakité, M., Rupp, F., Kern, J., 2011. Hydrothermal carbonization of anaerobically digested maize silage. Bioresour. Technol. 102 (19), 9255-9260. http://dx.doi.org/10.1016/j.biortech.2011.06.099.

NIST, 2015. Fluid Thermodynamic and Transport Properties, Version 5.0. <http:// webbook.nist.gov/chemistry/>

Pala, M., Kantarli, I.C., Buyukisik, H.B., Yanik, J., 2014. Hydrothermal carbonization and torrefaction of grape pomace: a comparative evaluation. Bioresour. Technol. 161, 255-262. http://dx.doi.org/10.1016/j.biortech.2014.03.052.

Pyo, S., Kim, M., Lee, S., Shi, H., Kim, J.T., Yoo, C.K., 2014. Developing a process-level vulnerability assessment index and evaluating mitigation strategies of GHG emission in waste treatment plants for climate change. In: Proc. 7th International Congress on Environmental Modelling and Software: Bold Visions for Environmental Modeling, pp. 2354-2361.

Rada, E.C., 2014. Energy from municipal solid waste. WIT Trans. Ecol. Environ. 190, 945-957. http://dx.doi.org/10.2495/EQ140892.

Rada, E.C. Ragazzi, M. Fiori, L. Antolini, D. 2009. Bio-drying of grape marc and other biomass: a comparison. Water Sci. Technol. 60 (4), 1065-1070. http:// dx.doi.org/10.2166/wst.2009.559.

Ragazzi, M., Rada, E.C., 2012. Multi-step approach for comparing the local air pollution contributions of conventional and innovative MSW thermo-chemical treatments. Chemosphere 89 (6), 694-701. http://dx.doi.org/10.1016/ j.chemosphere.2012.06.024.

Subagyono, D.J.N., Marshall, M., Jackson, W.R., Chaffee, A.L., 2014. Pressurized thermal and hydrothermal decomposition of algae, wood chip residue, and grape marc: a comparative study. Biomass Bioenergy 1-17. http://dx.doi.org/ 10.1016/j.biombioe.2014.08.020

Xiao, L.-P., Shi, Z.-J., Xu, F., Sun, R.-C., 2012. Hydrothermal carbonization of lignocellulosic biomass. Bioresour. Technol. 118, 619-623. http://dx.doi.org/ 10.1016/j.biortech.2012.05.060.

Yedro, F.M. García-Serna, J. Cantero, D.A. Sobrón, F. Cocero, M.J, 2014. Hydrothermal fractionation of grape seeds in subcritical water to produce oil extract, sugars and lignin. Catal. Today. http://dx.doi.org/10.1016/ j.cattod.2014.07.053. 